\title{
The Domain Constraint on Analogy and Analogical Argument
}

\author{
William R. BRown Quinnipiac College
}

Key Words: Domain constraint, issue (topic) relevance, folk logic, stare decisis, informal logic, selectional features, inductive (predictive) arguments from analogy, noninductive $(\mathrm{A}: \mathrm{B}: \mathrm{C}: \mathrm{D})$ analogical arguments.

\begin{abstract}
Domain constraint, the requirement that analogues be selected from "the same category," inheres in the popular saying "you can't compare apples and oranges" and the textbook principle "the greater the number of shared properties, the stronger the argument from analogy." I identify roles of domains in biological, linguistic, and legal analogy, supporting the account of law with a computer word search of judicial decisions. I argue that the category treatments within these disciplines cannot be exported to general informal logic, where the relevance of properties, not their number, must be the logically prior criterion for evaluating analogical arguments.
\end{abstract}

For what can synods have at all With bears that's analogical? Samuel Butler, Hudibras

Analogical arguments are subject, of course, to those criteria that apply to all arguments. Are there, in addition, criteria that apply uniquely to analogical arguments? In the particular case of analogical arguments (as well possibly as nonargumentative analogies) involving the $A: B:: C: D$ relation, is it possible, desirable, or necessary to formulate a rule specifying the category from which $\mathrm{A}, \mathrm{B}, \mathrm{C}$, or D must be selected? In the case of predictive ("inductive") arguments from analogy, must the target be in the same category as the sample? Such a rule, mutatis mutandis, might be applicable to analogical metaarguments as well. In its strong form, such a rule might say, "Analogical arguments can be cogent only if their analogues are selected from the same category," and in the weak form, "Other things being equal, analogical arguments whose analogues are selected from the same category justify a higher degree of confidence than do those whose analogues are not."

Is domain constraint in fact advocated by reputable authorities? Yes, it is implicit in all statements of the principle that, the more properties the analogues have in common, the stronger is the argument from analogy, a principle stated by Moore and Parker, Barry, Huppe and Kaminsky, and Runkle.' It is implicit in this principle for the obvious reason that, as the number of properties shared 
by a set of items increases, whatever definition of "same category" one might have stipulated will eventually be satisfied. As the population from which the sample is drawn is narrowed from "objects in he universe" to "vehicles" to "1990 Toyota Tercels" or something even more limited, a category will sooner or later be established that one is willing to call "the same." Not only is domain constraint always implicitly present in the number-of-shared-properties principle, but Runkle makes it perfectly explicit when he says, "What this principle does is to say that two things which share essential qualities are likely to be of the same species and thus instances of several generalizations." Huppe and Kaminsky are almost as explicit when they say, "We can argue that one tomato will be like all the others because one tomato is not different in any important respects from another, that is, tomatoes are generally considered to be homogeneous." Moore and Parker do not make domain constraint explicit but might as well since twelve of their thirteen examples in exercises do in fact conform to the "same category" principle and the thirteenth clearly appears intended to exemplify a fallacy.

All the authorities just cited are authors of logic or critical thinking texts, but the "same category" principle is also the basis of the distinction between literal and figurative analogies often found in rhetoric and speech communication texts. ${ }^{2}$

The domain constraint agenda would seem to face serious difficulties since it is hard to think of any non-vague, non-arbitrary way to define the term "same category." In addition, since any given item may be classified within a large number of different categories, there is the problem of determining what same category all items should belong to. Perhaps most important, it is unclear what would be gained by resolving these difficulties: why would an analogy be any the more satisfactory or an analogical argument have any the greater cogency for having all its analogues in the same category? The only purpose for the constraint that I can think of is to restrict to a sample or population that has the desired, relevant characteristics. I will contend that it would be more efficient to seek a relevance criterion directly rather than use the indirect means of the category restriction. One reason is that the category restriction requires the analogues to share a large number of irrelevant characteristics in addition to the small number (perhaps only one!) of necessary, relevant characteristics. Indeed, such a requirement appears to fall apart under the slightest pressure, as the following example illustrates.

Consider several variations on an analogical argument intended to affirm the legitimacy of an unofficial relationship. The internal structure of this argument is not presently at issue, and I will suppose, relying on the model proposed by Woods and Hudak, which appears to me at least as satisfactory as any other model I am aware of, that it has the underlying form of a metaargument which asserts that Argument $B$ stands or falls with Argument $A .^{3}$ The conclusion of Argument B is:
A couple can be authentically married without a ceremony or a certificate. Argument $\mathrm{A}$ has five alternative versions, the conclusions of which are labeled a) through e):

a) A person can be educated without enrolling in a school and being awarded a diploma or a degree at a graduation.

b) Guerrilla armies can fight wars without being recognized by national governments.

c) One can be a priest without being ordained. (The premises for this conclusion are indebted to Exodus 19: 6, 1st Peter 2: 5).

d) Those species of birds that form lifelong matings without official approval are not engaging in a reprehensible practice.

e) It is a legitimate practice for two authors to collaborate on a book without forming a corporation or legal partnership.

On the basis of category membership, it is impossible to decide which one of these variations is better than another. If sexual intimacy is the category in which membership is required, only "d" can possibly be acceptable, but if all the analogues are required to be human, " $\mathrm{d}$ " is the only variation ruled out by the category restriction. On the basis of there being a relation between two persons, only "e" qualifies. On the basis of a real value which exists without official sanction, all five variations qualify, including "b," which compares marriage with warfare. If marriage is defined as a Christian sacrament, "c" is the only acceptable analogy, but if we require the sacrament to involve a relation between two persons, no analogy whatever could be acceptable because marriage is the only sacrament that involves exactly two persons. At this point we reach the position taken by those who view all analogies as suspect: if all analogues must be in the same category and the category is defined precisely enough, cogent analogy becomes impossible, at least under the strong formulation of domain constraint.

Examples and considerations such as these suggest that category membership requirements enhance cogency haphazardly and inadequately if at all because they lack potency to insure issue relevance. Analysis of the issue to determine what features of the analogues are relevant to it is logically prior to determining category membership because it is the relevant features themselves that define the category the analogues should be assigned to.

Nevertheless, the principle for which I coin the name "domain constraint" is not only widely assumed in "folk logic" but also well established in more than one discipline and cannot be cursorily dismissed. After all, "As A is to B, So is C to D," like "Rewrite Sentence as Noun Phrase plus Verb Phrase," does have the look of an absurdly powerful generative rule in need of being tamed by selectional restrictions or other constraints so that it will generate all and only acceptable examples. Further, it is possible that domain constraint might be applicable to some types of analogies but not others or that it could be feasible within certain disciplines without being justifiable as a principle of informal logic in general. 
By "folk logic" I do not mean the logic (or illogic) people really use (sometimes called "natural logic"), but rather a body of popular beliefs about logic. The expression is intended to be more or less parallel with "folk etymology," a term long established in linguistics. Though often fallacious, popular beliefs are by no means always so, and by the use of the term I intend no aspersions on any particular logician or logical theory. Examples of folk logic beliefs are: 1) It's impossible to prove a negative; 2) An air-tight alibi proves a not guilty plea; 3) Deduction moves from the general to the specific and induction from the specific to the general; 4) Sherlock Holmes was a master of deduction, at least Conan Doyle often said so; 5) Being logical is a personality trait; 6) You can prove anything with statistics (said ironically); and most pertinent to the present discussion - 7) You can't compare apples with oranges.

As well as providing a key example from folk logic, I will identify applications of domain constraint characteristic of analogical reasoning in three disciplines: biology, linguistics, and law. This material is presented in the belief that readers of Informal Logic are interested in ways logic is used in various disciplines; logic purports, however, to be itself a discipline, not simply a description of disciplines, and I will also consider to what extent the theory and practice of analogy in informal logic itself can be compatible with that in other disciplines.

In order to attempt to ground domain constraint in "common sense" or "folk logic," I would like to consider and modify an example used by Woods and Hudak. ${ }^{+}$After discussing Thompson's famous analogy ${ }^{5}$ between the pregnant rape victim who seeks an abortion and the kidnapped woman who wants to sever her life-sustaining connection with the violinist, they consider as a comparison base an account of a Siamese twin who wants to sever the lifesustaining connection with the other twin. Suppose we go beyond Woods and Hudak's example by substituting this alternative base so as to construct a counter analogy against Thompson's argument. How would we evaluate the two analogies relative to each other? I believe a careful analysis will show the twin example to be irrelevant. One must recall that even though Thompson takes a pro choice position across the board in her essay, the violinist analogy in itself is not intended to establish anything so sweeping as the justification of abortion on demand or abortion in general. Its specific purpose, as Thompson makes quite clear, is to justify abortion in the case of rape (and in no other case) even assuming for the sake of argument that a foetus is a fully human person with a soul and so forth. This is the context that establishes the topic, to which any counteranalogy must be relevant. Thus it is obvious that the Siamese twin counteranalogy utterly fails the test of topic relevance: a Siamese twin is not the victim of a crime of violence, as is a woman who has been raped or kidnapped. The twin example is really an independent analogy relevant to a quite different topic, namely abortion in a situation where pregnancy is the result of neither forced sex nor voluntary sex. A woman born pregnant or one about to give virgin birth would be just about the only relevant analogue to the twin.

Nevertheless, the twin example has a strange appeal. In the pilot testing for a related project, some student subjects told me they had to admit it was a better analogy than the violinist even though it contradicted their own prochoice position. When I reported on that research to a faculty audience, seventeen of twenty-five faculty members voted for the twin as the better of the two analogies. After my analysis was presented, however, audience members reversed their opinion. I think this remarkable appeal can be accounted for on the basis of domain constraint. The plausibility of the twin results from the fact that it observes the constraint and the violinist does not. The twin is a close analogy though irrelevant, whereas the violinist is a relevant analogy though remote. Siamese twins are physically, that is "realistically" similar to a pregnant woman and her foetus in that they are blood relatives and are connected in an intimate, organic, natural, biological way more congruent with an umbilical cord than the artificial, mechanical tubes that hook the woman up to the musician. In other words, twinship and pregnancy are in the "same category," if "category" is defined in terms of physical similarity and conventional association." Folk logic assumes that physical properties are inherent and thus more "real" than abstract properties, which are seen as conferred and thus somehow "unreal." A wedding ring must belong to the same category as other items of jewelry because it is made of precious metals, and not to the same category as flags, bishops' miters, and military insignia because of its symbolic function.

This "common sense" view has had a pervasive influence for several centuries, as illustrated by Butler's satirical seventeenth-century poem from which my epigraph is taken, the Latin quotations with which that full passage is larded suggesting the derivation to be scholastic as well as popular, and it is even more ancient as Measell's account of the distinction between literal and figurative analogy makes clear. ${ }^{7}$ It has become a commonplace across the disciplines so that even in psychology Perkins may be found to maintain that remote or novel analogies are not more associated with creativity than close or stock analogies are, a distinction he illustrates by contrasting a comparison of veins in the arm to veins in the leg with a comparison of either to a network of roads on a map. ${ }^{*}$

Turning now to a consideration of domain constraint applications in the academic disciplines, we note that in biology the term "analogous" is reserved for contexts where the analogues are not in the "same domain." According to dictionaries and encyclopedias, the term "analogous" in biological usage refers to structures that are alike in form and function but different in evolutionary origin." Thus the wing of any insect is analogous to the wing of a bird or a bat but termites' wings are not analogous to bees' wings since termites and bees are both insects. For a biologist, sameness of domain or category is determined by 
common evolutionary origin rather than presence or absence of any particular feature such as wings. A somewhat similar restriction of the term "analogous" to cross-domain rather than within-domain contexts also sometimes appears in legal usage, as we shall soon see, but it is less characteristic of that discipline. One reason biologists conceive "category" as they do must be that terminology and phenomenon correspond so closely; the category seems to exist in nature itself rather than in science. It is hard to think of any classificatory term that appeals to the lay mind, and possibly to biologists themselves, as more "real" and less stipulative than "species."

The term "analogical change" and equivalent expressions are sometimes used in linguistics, where they refer to processes influencing the behavior of language users rather than to classificatory practices of linguists. Such behavior is usually the making of mistakes or the development of new forms on the model of already existing forms. The use of brung instead of brought on the analogy of sung is a typical example, but the process is historically much more pervasive, as indicated by the development of the "s" plural in English, which as O'Grady, Dobrovolsky, and Aronoff point out, is an extension of what was once the standard pattern for only a single class of nouns." These authors explain the process in standard inductive terms as "the inference that if elements are alike in some respects, they should be alike in others as well," but others use the proportional framework by citing "knowed is to know as rowed is to row." Steible captures this characteristic of speakers' behavior succinctly by referring to "the principle of analogy by which things are made alike because it seems that they ought to be alike." 12 Normally linguists do not refer to analogies across domains, such as semantics, morphology, and phonology, because the phenomenon being described is a behavior that takes place within a single area, such as the conjugation of verbs. Likewise, legal analogies normally are not made across legal areas such as tax law and divorce law, as will appear, but for different reasons.

Because analogy has been incorporated into law more prominently and on a more massive scale than anywhere else, I will consider this institution at greater length. I have provided quantified data and a quasi-random sample for such an examination by relying on a word search of the Westlaw database. By analyzing the context in which the words analogy and analogous occur in judicial decisions, it is possible to determine what sense the words are being used in, in each occurrence, and whether they are directly assuming, implying, or referring to a notion of domain. As it turns out, the type of domain involved is usually the branch of law that the case or the precedent falls under (such as tort, patent law, tax law, etc.), although occasionally it is a source of legal authority (such as the U. S. Constitution or the Supreme Court) or a jurisdiction (such as applying a precedent from a case in a New Jersey court to a present case in a New York court). ${ }^{13}$ For the present purpose I have ignored a variety of miscellaneous usages. ${ }^{1+}$ I have limited my treatment to the sixteen references clearly pertaining to analogies within the same branch of law and the eighteen clearly pertaining to analogies across branches of law. ${ }^{15}$

According to traditional textbook treatment, legal reasoning is based on the theory of stare decisis, according to which an instant case is decided by analogy with similar, precedent cases involving the same issue of law. ${ }^{16}$ An important constraint of this theory is that the two (or more) cases should be in the same branch of law. Even to the mind of the lay person imbued with a "common sense" or "folk logic" version of the domain constraint, it would probably appear obvious that there must be something improper about analogizing tax cases with divorce cases, but the legal version of the constraint is more technical and rigorous: cases involving train crashes normally should not be analogized with cases involving shipwrecks because, even though trains and ships may be classified within the "same category" by the lay mind, shipwrecks frequently fall within the purview of the Maritime Courts and most train crashes do not.

Numbers do not tell the whole story here. Eighteen references to acrossboundary precedents and sixteen to within-boundary ones may suggest that the domain constraint is being honored about as much in the breech as in the observance, but the tone in which justices cite across-boundary precedents is sometimes deprecatory or even apologetic. In his decision on a civil rights suit seeking damages for false arrest and police brutality, a multi-defendant civil case, Justice Newman spoke of the "analogy to the way some courts have handled somewhat similar problems in the field of tort law" and said, "We find the analogies sufficiently helpful to rely upon them at least for the limited purpose of developing a procedure for placing an admission in evidence in a multi-defendant civil trial."' Similarly, Justice Moore noted that "neither statutes nor decided cases furnish satisfactory guides" for certain extradition procedures and then appealed to "Federal Rules of Criminal Procedure, which, of course, are not directly applicable to extradition . . . but which are available for analogy purposes."

Can any of the factors that explain treatments of domain in law, "folk logic," and various disciplines justify a domain constraint requirement in informal logic in general? "Folk logic" and the literal-figurative distinction of rhetoric simply exemplify the problem rather than suggesting any resolution, the problem being the conflation of closeness with relevance, the inability to define sameness of category, and the lack of correlation between class membership and issue relevance. Certain disciplines resolve parts of the problem but in ways not easily transportable outside the boundaries of the particular discipline. Biology finds its categories virtually premade in nature itself, a convenience not often available to logicians. Law defines category by stipulation based on common branch of law, a system which has no obvious counterpart in informal logic. Linguistics successfully predicts linguistic behavior on the basis of rigorously defined linguistic categories such as "strong verb" and "weak verb," 
but informal logic usually falls short of this degree of rigor and is not exclusively in the business of predicting behavior.

One further difficulty besets the attempt to import legal conceptions of domain into informal logic. Unlike the traditional notion of domain elsewhere which imposes constraints on individual analogues, legal practice imposes the constraint on the case as a whole in terms of what jurisdiction or branch of law it is to be tried in. Related to the historical reasons for the development of separate branches of law, part of the legal notion of domain is authoritative rather than logical. Judges are constrained by the fact that tax law and labor law rest on different sets of statutes, which have been interpreted by different sets of court decisions-different sources of authority. More simply put, Maritime Courts just do not have authority over trains. An anonymous referee of Informal Logic has pointed out to me that there are logical reasons why a mobile home may be treated as a house in tax law and as a motor vehicle under the highway traffic act. This may readily be granted; however, the logic involved is not a matter of logical form. It is not a logic that can be exported to contexts outside the law, where a different logic might treat mobile homes as analogous to motor homes, yachts, or houseboats.

Finally, it appears that domain constraint must be defined differently for every discipline and area of thinking where it is to be found. Perhaps this consequence presents no conflict for those who share Stephen Toulmin's approach to the relation between logic and the disciplines, and indeed it would probably be welcomed by them, but for those of a different persuasion it may present a problem, as, for that matter, it might present one for those who disagree with John McPeck about the possibility of teaching thinking outside the context of a subject matter discipline.

Even if domain models from elsewhere do not support a domain constraint in informal logic, perhaps a case can still be made for the constraint that does not rely on external models. Noting that several types of analogy and analogical argument have been identified, we might suppose that domain constraint might be more applicable to some types than others, and it is the inductive, predictive concept of analogy where domain constraint has the greatest degree of intuitive plausibility. Some of this plausibility is vitiated, however, on close examination. For example, discussions of the probability of abolishing war on the analogy of the abolition of slavery, cited by Govier ${ }^{14}$, and speculations about the probability of conquering AIDS on the analogy of the conquest of smallpox both observe the domain constraint since diseases are being compared with diseases and war and slavery are both socio-political evils. Analogizing the eradication of socio-political evils with the eradication of diseases, however, would be unacceptable in terms of domain constraint. A case might well be made, however, for the proposal that the elimination of war is more analogous to the eradication of smallpox than it is to the abolition of slavery and that the conquest of AIDS is not analogous to any of the three other projects. This is true because the distinction between cause, prevention, treatment, cure, and eradication of diseases is more relevant than the distinction between diseases and socio-political evils. A cause or a cure requires a discovery whereas eradication requires the application of technology through a globally coordinated program. Thus the public health efforts which have brought smallpox to virtual extinction offer little if any analogical basis for research into the biochemical nature of the HIV virus. The elimination of war, on the other hand, requiring international cooperation and intervention across national boundaries, bears a good deal of parallelism with the anti-smallpox campaign - and very little with the plantation system indigenous to the American South in the middle nineteenth century. Thus it is possible for a socio-political evil to be more like a disease than it is like some other sociopolitical evil in certain relevant respects, even in an entirely inductive setting for strictly predictive purposes.

Inductive analogies frequently predict successfully without observing domain constraint. Consider proposals to introduce a procedure into one domain on the basis that the same or a similar procedure has been used in another domain, any proposal, for example, to transport technology into a new area, such as the development of the debit card for withdrawing money from the bank on the model of the credit card for making purchases, or the replacement of library card catalogues by computer systems on the model of similar uses of computers elsewhere. Similar reasoning may apply to ethical justification as well as technological feasibility, as in the practice of triage in famine relief on the model of triage in military medicine. The increasingly popular practice of holding retreats in all sorts of worldly, secular contexts on the analogy of spiritual, religious retreats is perhaps an example of the same type. All such adaptations are based on the inductive analogy that if Domain A and Domain B have various features in common and if Procedure $P$ was successful in Domain $A$, then Procedure $P$ will probably also be successful in Domain B. If the domain constraint were valid, such adaptations could not be reliably predicted.

I have paid particular attention to inductive analogical arguments because of the presumed plausibility of domain constraint in this type of reasoning. Extensive criticism of domain constraint as applied to noninductive analogical arguments, beyond what has already been said on that score, seems unnecessary. Indeed, if domain constraint were universally observed, few if any noninductive analogical arguments would ever be made outside controlled environments such as those of law.

I have contended thus far that specialized versions of domain constraint are feasible within the contexts of particular disciplines, notably law, that it is not feasible to generalize these versions beyond the boundaries of these disciplines, and that the version of domain constraint that has been conventional within informal logic is inadequate. I must admit that I have not proved that requiring analogues to be in "the same category" reduces rather than leaving 
unchanged or slightly increasing the degree of confidence we are entitled to have in the conclusions of arguments, nor have I proved that the number of potentially valuable arguments unnecessarily aborted by domain constraint is greater than the number of fallacious arguments it has protected us from. I presume, however, that I have succeeded in demonstrating several deficiencies in it. What, then, do I propose to substitute for it? I submit the following:

The domain from which analogues may properly be selected is the population of those items that possess characteristics that are relevant to the conclusion of the argument. Furthermore, analogues must bear to each other a relation that is necessary to the articulation of the question at issue.

Conventional domain constraint assumes that a sample from this population can be obtained by requiring the analogues to belong to a conventional category. My proposal attempts to define the population directly by identifying the characteristics that are relevant. I call the relevant characteristics "selectional features." (I find the terms "sample" and "population" regrettable since a pseudo-statistical aura attaching to the concept of analogy is the last thing I want to encourage, but the currency of "sample" makes my usage unavoidable).

Making the relevance criterion logically prior (rather than appealing to it almost as an afterthought) and relying on selectional features rather than category membership make the proposal context sensitive and efficient. Allowing a car to be analogized with oil fired furnaces that have cracked gaskets (a single shared property, which is relevant) makes sense in the context where one already owns a car with an oil leak and wants to repair the leak. Requiring that this particular car be analogized only with other cars of the same year, make, and model that have developed an oil leak (many shared properties, only one of which may be relevant) blocks this context, is appropriate only in the context where one is deciding whether to buy the particular car, and is inefficient since it is effective only to the extent that its number-of-sharedproperties principle happens to catch a relevant property in its net.

Analyzing the situational context according to a relevance criterion to identify the appropriate selectional feature before considering category membership rather than after enables us to evaluate competing analogies. A Republican landslide in a U. S. election might be either a destructive or a constructive event depending on one's point of view, but in either case it is more appropriately analogized to an earthquake than to a hurricane, as revealed by identifying the relevant selectional feature "resulting from long-term buildup of pressure" as opposed to "rapidly developing disturbance." Requiring the analogues to be selected according to membership in the three categories "atmospheric disturbance," "natural disaster," and "destructive event" would have blocked rather than facilitating discovery of this relevant feature.

Most recent work on relevance has focussed on relations between premise and conclusion. ${ }^{20}$ Analogical arguments, like all arguments, have premises, which should be relevant to their conclusions. ${ }^{21}$ In addition, however, the relevance of argument to issue is especially crucial to analogical arguments.
Informal logic must deal not only with conventional domains but also, on a case by case basis, with categories newly created according to the needs of ongoing discourse.

\section{Notes}

'Brooke Neal Moore and Richard Parker, Critical Thinking, 3rd ed. (Mountain View, Ca., Mayfield, 1992), p. 317; Vincent Barry, Good Reason For Writing (Belmont, Ca., Wadsworth, 1983), p. 144; Bernard F. Huppe and Jack Kaminsky, Logic and Language (New York, Knopf, 1962), p. 203; Gerald Runkle, Good Thinking: an Introduction to Logic, 2d ed. (New York, Holt, 1981), pp. 224, 221.

${ }^{2}$ As documented in my article, "Two Traditions of Analogy," Informal Logic XI, No. 3 (Fall 1989), pp. 161-172.

${ }^{3}$ John Woods and Brent Hudak, "By Parity of Reasoning," Informal Logic XI, No. 3 (Fall 1989), pp. 125-140.

${ }^{4}$ Ibid.

3 Judith Jarvis Thompson, "In Defense of Abortion," Philosophy and Public Affairs, I, No. 1 (Fall 1971), pp. 437-61.

${ }^{6} \mathrm{I}$ use the word domain, not in the sense of a mathematical mapping of functions, but both in the sense of an area controlled by an authority (the king's domain) and in the sense of a field of subject matter (the domain of history). I am attempting to capture the common sense connotation of something naturally or conventionally existing rather than constructed or created by attribution like a class or a category

'James S. Measell, "Classical Bases of the Concept of Analogy," The Journal of the American Forensic Association 10 (1973), pp. 1-10.

${ }^{8}$ David N. Perkins, "Novel Remote Analogies Seldom Contribute to Discovery," Journal of Creative Behavior 17 (1983), pp. 223-239.

'The New Columbia Encyclopedia 1975, article "Analogous."

${ }^{10}$ William O'Grady, Michael Dobrovolsky, Mark Aronoff, Contemporary Linguistics an Introduction, 2nd ed. (New York, St. Martins, 1991), p. 273.

"Franklin C. Southworth and C. J. Daswani, Foundations of Linguistics (New York: MacMillan, 1974), p. 284

${ }^{12}$ Daniel J. Steible, Concise Handbook of Linguistics (New York: Philosophical Library, 1967), p. 16

${ }^{13}$ The selection was made by identifying every occurrence of the words analogy or analogous in the decisions of the U. S. Court of Appeals For the Second Circuit for the month of December at five-year intervals from 1895 to 1990 . This procedure yielded fiftyseven hits in forty-five decisions written by twenty-six justices. I want to thank Larry Raftery, Reference Librarian of the Quinnipiac College School of Law, for valuable assistance.

${ }^{1+}$ Such as references to analogous statutes, regulations, or other legal sources of authority other than judicial decisions, a trial judge's comparison of the case to exploratory surgery which may turn up a malignant growth, and instances where the word analogous means nothing more specific than the word similar.

${ }^{\text {is }}$ My decisions on attribution are, of course, those of a lay person, not a lawyer.

The notation system followed here is illustrated by the first hit of the sixteen employing the same-branch sense: Kluchnik v. Lehigh Valley Coal Co, 228 F. 880 at 882 . This 
means the decision in the case named is found in Vol. 228 of The Federal Reporter beginning on p. 880 and the word analogy or analogous occurs on p. 882 . The other hits employing this sense are: Loma Fruit Co v. International Nav Co, 11 F. $2 \mathrm{~d} 124$ at 127. Higgons v. Pratt Institute, 45 F. 2d 698 at 700 . The Mauretania, 80 F. $2 \mathrm{~d} 225$ at 227 twice. C.I.R. v. Barolzheimer, 116 F. $2 \mathrm{~d} 628$ at 630 . Weil v. U.S. 115 f. $2 \mathrm{~d} 999$ at 1000 . Redman v. United Fruit Co, 185 F. 2d 553 at 553. U.S. v. Kellerman, 43I F. 2d 319 at 322. In re Master Key Antitrust Litigation, 528 F. 2d 5 at 11. U.S. ex rel Pella v. Reid, 527 F. 2d 380 at 385. National Ornament and Electric Light Christmas Ass'n, Inc. v. Consumer Product Safety Commission, 526 F. 2d 1368 at 1373 . Rosen v. Dick, 639 F. 2d 82 at 94 . Baden v. Koch, 638 F. $2 d 486$ at 493, 495. Direct Marketing Ass'n, Inc v. U.S. Postal Service, 778 F. 2 d 96 at 110 .

The hits employing the across-branch sense are: re Milne, 185 F. 2d 244 at 249. Osgoodby v. Talmadge, 45 F. 2d 696 at 698 . The Mauretania, 80 F. 2d 225 at 228 N.L.R.B. v. Inernational Hod Carriers, 228 F. $2 d 589$ at 591. Rieser v. Baltimore and Ohio Railroad, 228 F. 2d 563 at 564 footnote \#1. First National City Bank of New York v. Aristeguieta, 287 F2d 2190 at 222, 223, 226. U.S. v. St. Regis Paper Co, 285 F. 2d 607 at 614 twice. U.S. v. Davis, 353 F. 2d 614 at 617. O'Neal v. Esty, 637 F. $2 d 846$ at 851 twice. U.S. v. Sindona, 636 F. 2d 792 at 804. Pinkney v. Keane, 920 F. 2d 1090 at 1099 Signorelli v. Evans, 637 F. 2d 853 at 861, 862. Butts v. City of New York, 779 F. 2d 141 at 147 .

${ }^{16}$ This theory will not be elaborated here, and the reader is referred to such standard texts as Edward H. Levi, An Introduction to Legal Reasoning (Chicago: Univ. of Chicago Press, 1948), and Steven J. Burton, An Introduction to Law and Legal Reasoning (Boston: Little Brown, 1985).

${ }^{17} \mathrm{O}$ 'Neal v. Esty, 637 F. 2d 846 at 851.

${ }^{18}$ First National City Bank.

${ }^{19}$ Trudy Govier, "Analogies and Missing Premises," Informal Logic XI, No. 3 (Fall 1989), p. 142

${ }^{20}$ See especially J. Anthony Blair, "Premise Relevance" in Robert Maier, Norms in Argumentation (Dordrecht: Foris, 1989), pp. 67-84. George Bowles, three articles in Informal Logic: "Favorable Relevance and Arguments" XI, No. 1 (Winter 1989), pp. 11 17. "Propositional Relevance," XII, No. 2 (Spring 1990), pp. 65-77. "Evaluating Arguments: the Premise-Conclusion Relation," XIII, No. 1 (Winter 1991), pp. 1-19.

${ }^{21}$ See John Woods and Brent Hudak, Op. Cit., for a discussion of the logical form of analogical meta-arguments.

WILLIAM R. BROWN DEPARTMENT OF ENGLISH

QUINNIPIAC COLLEGE HAMDEN, CT 06518 